This is an electronic reprint of the original article. This reprint may differ from the original in pagination and typographic detail.

Author(s): Portegijs, Erja; Rantakokko, Merja; Viljanen, Anne; Rantanen, Taina; Iwarsson, Susanne

Title: $\quad$ Perceived and objective entrance-related environmental barriers and daily out-ofhome mobility in community-dwelling older people

Year: $\quad 2017$

Version:

Please cite the original version:

Portegijs, E., Rantakokko, M., Viljanen, A., Rantanen, T., \& Iwarsson, S. (2017).

Perceived and objective entrance-related environmental barriers and daily out-ofhome mobility in community-dwelling older people. Archives of Gerontology and Geriatrics, 69, 69-76. https://doi.org/10.1016/j.archger.2016.11.011

All material supplied via JYX is protected by copyright and other intellectual property rights, and duplication or sale of all or part of any of the repository collections is not permitted, except that material may be duplicated by you for your research use or educational purposes in electronic or print form. You must obtain permission for any other use. Electronic or print copies may not be offered, whether for sale or otherwise to anyone who is not an authorised user. 


\section{Perceived and objective entrance-related environmental barriers and daily out- of-home mobility in community-dwelling older people}

Erja Portegijs ${ }^{a}, \mathrm{PhD}$, Merja Rantakokko ${ }^{\mathrm{a}}, \mathrm{PhD}$, Anne Viljanen ${ }^{\mathrm{a}}, \mathrm{PhD}$, Taina Rantanen ${ }^{\mathrm{a}}, \mathrm{PhD}$, Susanne Iwarsson ${ }^{\mathrm{b}}, \mathrm{PhD}$

${ }^{a}$ Gerontology Research Center and Department of Health Sciences, University of Jyvaskyla, Finland

${ }^{b}$ Department of Health Sciences, Lund University, Sweden

Erja Portegijs, erja.portegijs@jyu.fi

Merja Rantakokko, merja.rantakokko@jyu.fi

Anne Viljanen, anne.viljanen@jyu.fi

Taina Rantanen, taina.rantanen@iyu.fi

Susanne Iwarsson, susanne.iwarsson@med.lu.se

Corresponding author:

Erja Portegijs

Gerontology Research Center and Department of Health Sciences

P.O. Box 35 (viv)

FI-40014 University of Jyvaskyla

Finland
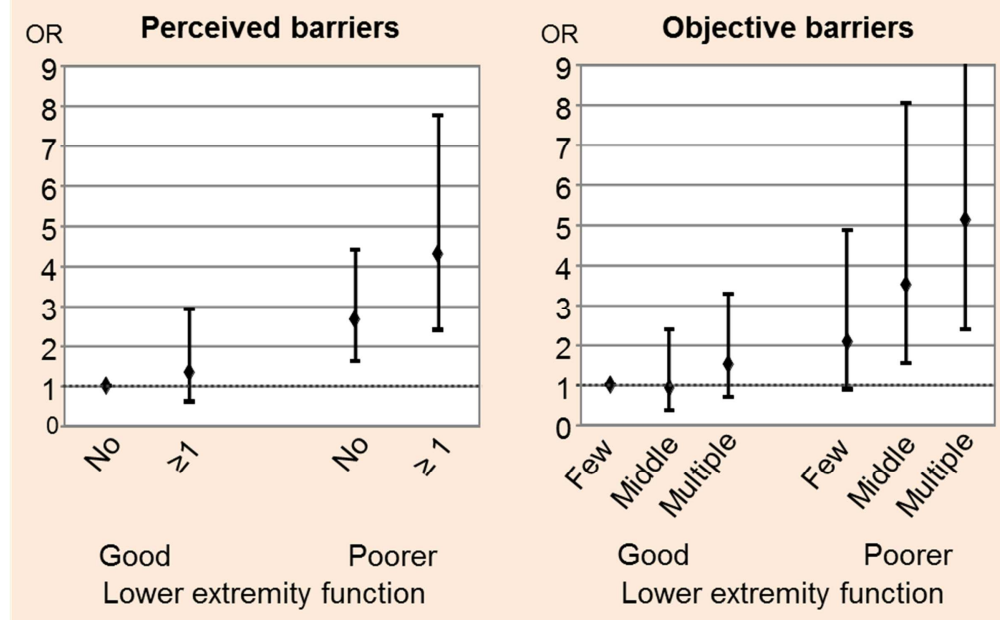

\section{HIGHLIGHTS}

- Objective and perceived home entrance-related barriers are weakly associated

- Older people with poor functional capacity are susceptible to environmental barriers

- Environmental barriers at the home entrance may limit out-of-home mobility

- Barriers in close exterior surroundings may not compromise out-of-home mobility 


\section{ABSTRACT}

Purpose. We studied whether entrance-related environmental barriers, perceived and objectively recorded, were associated with moving out-of-home daily in older people with and without limitations in lower extremity performance.

Methods. Cross-sectional analyses of the "Life-space mobility in old age" cohort including 848 community-dwelling 75-90-year-old of central Finland. Participants reported their frequency of moving out-of-home (daily vs. 0-6 times/week) and perceived entrance-related environmental barriers (yes/no). Lower extremity performance was assessed (Short Physical Performance Battery) and categorized as poorer (score 0-9) or good (score 10-12). Environmental barriers at entrances and in exterior surroundings were objectively registered (Housing Enabler screening tool) and divided into tertiles. Logistic regression analyses were adjusted for age, sex, number of chronic diseases, cognitive function, month of assessment, type of neighborhood, and years lived in the current home.

Results. At home entrances a median of 6 and in the exterior surroundings 5 environmental barriers were objectively recorded, and $20 \%$ of the participants perceived entrance-related barriers. The odds for moving out-of-home less than daily increased when participants perceived entrance-related barrier(s) or when they lived in homes with higher numbers of objectively recorded environmental barriers at entrances. Participants with limitations in lower extremity performance were more susceptible to these environmental barriers. Objectively recorded environmental barriers in the exterior surroundings did not compromise out-of-home mobility.

Conclusion. Entrance-related environmental barriers may hinder community-dwelling older people to move out-of-home daily especially when their functional capacity is compromised. Potentially, reducing entrance-related barriers may help to prevent confinement to the home.

Keywords. Environment, mobility limitation, aging, housing, outdoor mobility, physical activity 


\subsection{INTRODUCTION}

Declining health and functional capacity increase the risk of physical inactivity in old age, which in turn leads to further health decline. ${ }^{1}$ Physical activity tends to increase when an individual leaves the home. ${ }^{2,3}$ In addition, leaving the home daily is associated with better health and function in community-dwelling older people, ${ }^{4,5}$ and enables older people to participate in meaningful activities. ${ }^{6,7}$ Consequently, low frequencies of moving out-of-home may threaten independence and quality of life of community-dwelling older people. ${ }^{6,8,9}$ In addition to personal factors, environmental factors have been associated with community mobility of an individual. ${ }^{10,11}$ The neighborhood environment may motivate people to leave home and be physically active (e.g. parks or services), while it may also pose barriers for mobility (e.g. poor road conditions or long distances). ${ }^{12,13}$ However, relationships between features of the neighborhood environment and physical activity and walking behavior are inconsistent for older people. ${ }^{14}$ Entrancerelated environmental barriers, which are located at the home entrance or in the close exterior surroundings, are the first obstacles an individual may encounter in the physical environment when leaving the home. While hitherto not investigated, these entrance-related environmental barriers may reduce the frequency of out-of-home mobility.

According to the ecological theory of aging and the notion of person-environment fit, ${ }^{15}$ an individual's behavior depends on personal factors (e.g. lower extremity performance) and environmental factors (e.g. obstacles in the natural and built environment). Barriers in the built environment may be professionally assessed either objectively through direct observation against preset criteria or by using self-rating to capture older people's perceptions of such barriers. Objectively assessed barriers may not impede mobility for everyone, as mobility is largely dependent on the functional capacity of the individual. ${ }^{16,17}$ Perceptions of environmental barriers, on the other hand, take into account personal and environmental factors as well as the desired activities of an individual. ${ }^{15,18}$ Thus, such perceptions may be more closely related to the actual behavior, e.g. out-of-home mobility, of an individual. However, people with functional limitations may not be exposed to physical environmental barriers due to activity restriction ${ }^{19,20}$ and consequently remain unaware of the accessibility problems related to a suboptimal person-environment fit. Alternatively, according to the model of selective optimization and compensation, ${ }^{21}$ individuals with functional limitations may find ways to cope with physical environmental barriers (e.g. poor lighting in a familiar environment) or effectively compensate for them (e.g. installation of handrails at entrance stairs) to maintain their activity.

Guidelines and policy for environmental planning and construction commonly target objective aspects of the environment. ${ }^{22}$ Accordingly, it is important to increase the understanding of relationships between objective and perceived environmental barriers in and around the home and how such barriers and relationships affect mobility behavior of older people with and without functional limitations. Especially in older populations, the relationship between objective and perceived environmental barriers is not clear. ${ }^{23-}$ 
${ }^{25}$ Yet, objective and perceived aspects of housing are associated with different health outcomes, in particular activities of daily living ${ }^{24,26-28}$ and falls. ${ }^{17,26,27}$ In addition, previous studies have demonstrated associations between housing aspects and physical activity ${ }^{16}$ as well as the frequency and difficulty of participation in community activities among older people. ${ }^{11}$ To the best of our knowledge there is a paucity of research studying relationships between housing aspects and out-of-home mobility in old age.

The aims of the current study were to explore 1) the association between objectively recorded and perceived entrance-related environmental barriers for mobility at home entrances and in the close exterior surroundings among community-dwelling older people with and without lower extremity performance limitations, and 2) whether objectively recorded and perceived environmental barriers were associated with moving out-of-home on a daily basis among community-dwelling older people with and without lower extremity performance limitations. Objective environmental barriers for mobility at home entrances and in the close exterior surroundings were studied separately, while perceived entrance-related barriers scale included items of both dimensions.

\subsection{MATERIALS AND METHODS}

\subsubsection{Study design and recruitment}

This study was based on cross-sectional analyses of baseline data of the "Life-space mobility in old age" (LISPE) cohort study in community-dwelling, 75-90-years-old people, living in the municipalities of Muurame and Jyväskylä in central Finland. The study methods, including non-respondent analyses, have been published previously. ${ }^{29}$ In summary, a random sample of 2550 people was informed with a letter about the study. Willingness and eligibility for participation (living independently, able to communicate, and residing in the recruitment area) were determined during a phone interview. At the home visits for the baseline data collection, participants also signed an informed consent form $(\mathrm{N}=848)$. The LISPE study was approved by the Ethical Committee of the University of Jyväskylä, Finland.

\subsubsection{Main instruments}

Moving out-of-home daily (yes vs. less often), i.e. an indicator of out-of-home mobility, was assessed using a self-report question of how many days a week a participant moved outside his/her home during the preceding four weeks (according to the life-space assessment ${ }^{7}$ ). Participants reporting to move in their neighborhood, town or beyond were also considered to have moved outside their home.

Lower extremity performance, i.e. an indicator of functional capacity, was objectively assessed by the Short Physical Performance Battery, comprising of three tests that assess standing balance, walking speed over 2.44 meters, and five timed chair rises. Each task was rated according to established age- 
and gender-specific cut-off points, and a sum score (range 0-12) was calculated. ${ }^{30,31}$ Higher scores indicate better performance. In order to stratify the sample for the analyses, participants were categorized according to a dichotomization based on the median of lower extremity performance (short physical performance score 10).

Two sections of the Housing Enabler Screening Tool were used to objectively assess environmental barriers at the entrance and in the exterior surroundings of the home. ${ }^{32}$ The Housing Enabler is based on current national standards and guidelines for good housing design. ${ }^{33}$ The screening tool contained 17 items on close exterior surroundings (passenger loading zone far, narrow path, irregular surface, unstable surface, steep gradients, routes with steps, no/insufficient cues of level changes/hazards, high curbs, curbs with abrupt sides, no handrails on steep gradients, no/too few resting places on slopes, poor lighting, no/too few seating places, steps/level changes to refuse bin, steps/level changes to mailbox, refuse bin difficult to reach, and mailbox difficult to reach) and 11 items on entrances (narrow door openings, thresholds/steps at entrance, insufficient maneuvering space at doors, no resting area in front of entrance door, heavy doors, door that close quickly, complicated/illogical opening procedure, stairs the only route, high/low/irregular heights of risers, no/one-sided handrail, and handrails too short). During the home visit, trained assessors evaluated the home entrance and the exterior surroundings of the home using the screening tool rating each environmental barrier as present / not present. For each environmental barrier section, the total number of barriers identified and, subsequently, tertiles (few, intermediate, and multiple barriers) were calculated.

The presence of perceived entrance-related barriers (none vs. at least 1) was based on 7 self-rated questions. Participants were asked to rate whether each environmental feature (outdoor stairs, indoor stairs, slippery floor surface, poor lighting, doors, lack of storage space for assistive aids, other) hindered their mobility. ${ }^{29}$

\subsubsection{Confounding variables}

The demographic variables age, sex and time lived in the current home, calculated based on the date of the latest address change were derived from the national register. The assessment month (January (1)-June (6)) was used to account for climatological circumstances. Type of neighborhood (high-rise urban area, low-rise urban area, sparsely build residential areas, rural area) was derived from a Geographical Information System (GIS) data (OIVA information service, Finland's environmental administration). Self-reported number of chronic diseases was calculated from a list of 22 physiciandiagnosed chronic diseases and an additional open-ended question about any other physician diagnosed chronic conditions. ${ }^{34}$ Cognitive function was assessed using the 30 -item Mini-Mental State Examination (MMSE), with a score range of 0-30 and higher scores indicating better cognitive functioning. ${ }^{35}$ 


\subsubsection{Statistical analyses}

Twelve participants with missing data on objectively recorded environmental barriers $(n=3$; interview not conducted in the home) or the lower extremity performance assessment ( $n=9$; due to temporary medical condition, wheel chair use, severe visual impairment, lack of suitable chair, unwillingness to cooperate) were excluded from all analyses. The date of the latest address change was missing for 25 participants, due to a move or death between the baseline data collection and date of retrieval December 2012. For these participants the missing values of the time in the current home were imputed with the group average. Sensitivity analyses showed that this did not affect the results markedly. Thus all analyses include in total 836 participants. Group differences in participant characteristics between those moving or not moving out-of-home daily were tested with the Mann-Whitney $U$ tests or Chi-square tests.

Spearman correlation coefficients between the environmental barrier variables were calculated for all participants as well as for those with and without lower extremity performance limitations, respectively. In addition, cross-tabulation and bivariable logistic regression analyses (with perceived entrance-related barriers as the dependent variable) were conducted using the tertiles of objectively recorded environmental barriers (at entrances and in the exterior surroundings, respectively) to further explore the association between objectively recorded and perceived environmental barriers.

The tertiles of objectively recorded environmental barriers (at entrances and in the exterior surroundings, respectively) and the presence of perceived entrance-related barriers were included in bivariable logistic regression analyses to calculate the odds for moving out-of-home less than daily, for all participants as well as for participants with lower extremity performance above or below the median. All bivariable analyses were adjusted for age and sex. The number of chronic diseases, cognitive function, month of assessment, type of neighborhood, and the number of years lived in the current home were each added to the model one at a time to determine potential confounding effects; only fully adjusted models are reported.

The weak relationship between objectively recorded and perceived environmental barriers, identified in previous steps of the analyses $\left(R_{s} \leq .273\right)$, justified computing multiple logistic regression models to estimate the odds ratio for going out-of-home less than daily; simultaneously including all objective and perceived environmental barrier variables. This allowed us to determine whether each factor had an independent effect on out-of-home-mobility.

In order to study the combined effect of lower extremity performance and environmental barriers on out-of home mobility, dummy variables were created grouping participants based on lower extremity performance and tertiles of objective or perceived entrance-related barriers, respectively. Subsequently, 
the previously described bivariable logistic regression analyses were repeated using the dummy variables as independent variables in the models estimating the odds for moving out-of-home less than daily.

IBM SPSS Statistics 20 (IBM, Armonk, NY, USA) was used for statistical analyses, and statistical significance was set at $\mathrm{P}<.05$.

\subsection{RESULTS}

\subsubsection{Participant characteristics}

The participants were on average $80.6 \pm 4.3$ years-old and $64 \%$ were women. Of the participants, $15.4 \%$ $(\mathrm{N}=131)$ reported moving out-of-home less than daily. Table 1 shows that participants moving out-ofhome less than daily were older and comprised a higher proportion of women than participants moving out-of-home on a daily basis. In addition, more of those going out-of-home less than daily lived in highrise urban areas, they had a greater number of chronic diseases, had poorer median scores of lower extremity performance and cognitive function compared to those with daily out-of-home mobility.

Table 1. Participant characteristics of those moving out-of-home daily or less than daily $(\mathrm{N}=848)$.

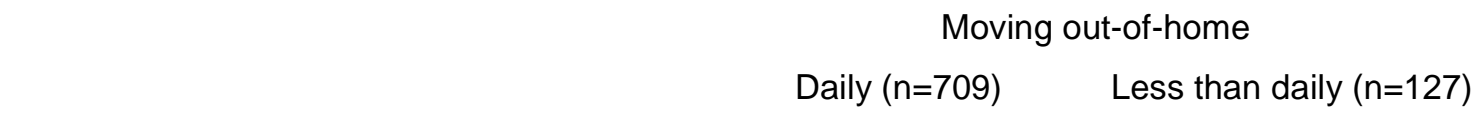

\begin{tabular}{lccccr} 
& Median & IQR & Median & IQR & $\mathrm{P}^{\text {a }}$ \\
\hline Age (yrs) & 79.7 & 7.0 & 83.1 & 6.1 & $<.001$ \\
Chronic diseases (n) & 4 & 4 & 5 & 4 & $<.001$ \\
Cognitive function (range 0-30) & 27.0 & 3 & 27.0 & 4.0 & .502 \\
Lower extremity performance (range 0-12) & 11 & 3 & 9 & 6 & $<.001$ \\
Time in current home (yrs) & 23.0 & 25.0 & 20.0 & 25.0 & .508
\end{tabular}

Sex

$\% \quad \mathrm{n} \quad \% \quad \mathrm{n} \quad \mathrm{P}^{\mathrm{b}}$

$\begin{array}{llllll}\text { Male } & 40 & 283 & 25 & 32\end{array}$

Neighborhood

$\begin{array}{rcccc}\text { High-rise urban area } & 48 & 338 & 76 & 97 \\ \text { Low-rise urban area } & 44 & 309 & 17 & 22 \\ \text { Sparsely build residential areas } & 5 & 32 & 6 & 7 \\ \text { Rural area } & 4 & 30 & 1 & 1\end{array}$

${ }^{a}$ Mann-Whitney $U$ test ${ }^{b}$ Chi-square test 


\subsubsection{Objectively recorded and perceived environmental barriers}

The median number of objectively recorded environmental barriers at entrances was 6 (IQR 3) and in the exterior surroundings 5 (IQR 3); very few participants (0.5\%) lived in a home without any such barriers.

The median number of perceived environmental barriers was 0 (IQR 0); $80 \%$ of the participants perceived no entrance-related barriers, $13 \%$ perceived one and $6.5 \%$ perceived multiple barriers.

The correlation between the number of perceived environmental barriers and the number of objectively recorded environmental barriers at entrances was weak but statistically significant $(R=0.210, p<.001)$ and was similar in participants with above and below median lower extremity performance $(R=0.186$ and $R=0.273, p<.001$, respectively). Accordingly, Table 2 shows that those living in a home with multiple objectively recorded barriers at the entrance were more likely to perceive entrance-related barriers regardless of the level of lower extremity performance. Environmental barriers in the exterior surroundings were not associated with perceived entrance-related barriers. 
Table 2. The prevalence of categorized objective environmental barriers (tertiles) and odds ratio (OR and $95 \%$ confidence interval) for perceived entrance-related barrier(s) in all participants and in those with lower extremity performance above or below the median.

Perceived barrier(s)

\begin{tabular}{|c|c|c|c|c|c|c|c|c|c|c|}
\hline & \multicolumn{4}{|c|}{ Perceived barrier(s) } & \multicolumn{6}{|c|}{ Bivariable logistic regression analyses $^{a}$} \\
\hline & \multicolumn{2}{|c|}{ Yes $(N=164)$} & \multicolumn{2}{|c|}{ No $(\mathrm{N}=672)$} & \multicolumn{2}{|c|}{ All $(\mathrm{N}=836)$} & \multicolumn{2}{|c|}{$\begin{array}{c}\text { Lower extremity } \\
\text { performance below the } \\
\text { median }^{\mathrm{b}}(\mathrm{N}=309)\end{array}$} & \multicolumn{2}{|c|}{$\begin{array}{l}\text { Lower extremity } \\
\text { performance at the median } \\
{ }^{\mathrm{b}} \text { or above }(\mathrm{N}=527)\end{array}$} \\
\hline & $\%$ & $\mathrm{~N}$ & $\%$ & $\mathrm{~N}$ & OR & $95 \% \mathrm{Cl}$ & OR & $95 \% \mathrm{Cl}$ & OR & $95 \% \mathrm{Cl}$ \\
\hline \multicolumn{11}{|l|}{ Objective - Entrance section } \\
\hline Few barriers & 16.5 & 27 & 37.5 & 252 & 1.0 & & 1.0 & & 1.0 & \\
\hline Intermediate barriers & 25.6 & 42 & 28.7 & 193 & 1.9 & $1.1-3.2$ & 1.9 & $.9-4.0$ & 1.9 & $0.8-4.4$ \\
\hline Multiple barriers & 57.9 & 95 & 33.8 & 227 & 3.5 & $2.1-5.7$ & 3.5 & 1.7-7.1 & 4.0 & $1.9-8.5$ \\
\hline \multicolumn{11}{|l|}{ Objective - Exterior section } \\
\hline Few barriers & 39.0 & 64 & 34.5 & 232 & 1.0 & & 1.0 & & 1.0 & \\
\hline Intermediate barriers & 29.3 & 48 & 32.1 & 216 & 0.8 & $.5-1.3$ & 0.9 & $.5-1.7$ & 0.8 & $0.4-1.6$ \\
\hline Multiple barriers & 31.7 & 52 & 33.3 & 224 & 0.9 & $.6-1.4$ & 1.0 & $.6-1.9$ & 0.9 & $0.5-1.6$ \\
\hline
\end{tabular}


Table 3. Bivariable logistic regression analyses estimating the odds ratios (OR and $95 \%$ confidence interval) for reporting to move out-of-home less than daily in all participants and in those with lower extremity performance above or below the median.

$$
\text { All }(\mathrm{N}=836)
$$

Age \& sex adjusted Fully adjusted ${ }^{\mathrm{b}}$

$\mathrm{N}$

OR $\quad 95 \% \mathrm{Cl} \quad$ OR $95 \% \mathrm{Cl}$

Lower extremity performance below the median ${ }^{\text {a }}(\mathrm{N}=309)$

Fully adjusted ${ }^{\mathrm{b}}$

OR

$95 \% \mathrm{Cl}$

1.0

1.7

$0.7-2.4$

Intermediate barriers 235

Multiple barriers 322

1.5

0.8-2.6

1.3

2.4

1.5-4.0

1.8

1.1-3.1

Objective - Exterior section

2.3

0.8-3.8

$1.1-4.9$

\section{Few barriers 296 \\ Intermediate barriers 264}

Multiple barriers 276

1.0

1.0

1.0

$.4-1.1$

0.5

0.6

0.4-1.03

0.6

.4-1.01

0.6

1.0

No $672 \quad 1.0$

1.5-3.5 $\quad 1.8$

1.2-2.9

1.0

1.6

Lower extremity performance at the median or above ${ }^{a}(\mathrm{~N}=527)$

Fully adjusted ${ }^{\mathrm{b}}$

OR $\quad 95 \% \mathrm{Cl}$

${ }^{a}$ Short Physical Performance Battery cut-off score 10

${ }^{\mathrm{b}}$ Adjusted for age, sex, number of diseases, cognitive function, month of assessment, type of neighborhood, and years lived in current home NOTE: Statistically significant relationships $(p<.05)$ are indicated in bold. 


\subsubsection{Environmental barriers and moving out-of-home}

Bivariable logistic regression analyses showed that participants living in homes with multiple objectively recorded environmental barriers at the entrance and those reporting perceived entrance-related barrier(s) had increased odds ratios (OR) to report moving out-of-home less than daily compared to those living in a home with few barriers (Table 3), also after adjustment for age, sex, number of diseases, cognitive function, month of assessment, type of neighborhood, and years lived in the home. When analyzing the results according to the level of lower extremity performance, the same pattern with higher OR was found for participants with lower extremity performance below the median but not in those at the median or above. For objectively recorded environmental barriers in exterior surroundings, those with lower extremity performance below the median and living in a home with intermediate numbers of environmental barriers had lower OR for reporting moving out-of-home less than daily than those living in a home with few environmental barriers.

Table 4 shows that in the multiple logistic regression models perceiving entrance-related environmental barriers and living in a home with multiple objectively recorded environmental barriers at the entrance both independently increased the OR to report moving out-of-home less than daily. In the same model, living in a home with multiple environmental barriers in the exterior surroundings lowered the OR statistically significantly. Among participants with a lower extremity performance below the median, only objectively recorded environmental barriers at entrances and exterior surroundings were associated with moving out-of-home less than daily while perceived environmental barriers were not. 
Table 4. Multiple logistic regression models estimating the odds ratios (OR and 95\% confidence interval) for reporting to move out-of-home less than daily in all participants and in those with lower extremity performance above or below median.

$$
\text { All }(\mathrm{N}=836)
$$

Age \& sex adjusted

Fully adjusted ${ }^{\mathrm{b}}$
Lower extremity performance

below the median ${ }^{\text {a }}(\mathrm{N}=309)$
Lower extremity performance at the median or above ${ }^{\text {a }}(\mathrm{N}=527)$

\begin{tabular}{|c|c|c|c|c|c|c|c|c|}
\hline & \multicolumn{2}{|c|}{ Age \& sex adjusted } & \multicolumn{2}{|c|}{ Fully adjusted ${ }^{\mathrm{b}}$} & \multicolumn{2}{|c|}{ Fully adjusted ${ }^{\mathrm{b}}$} & \multicolumn{2}{|c|}{ Fully adjusted ${ }^{\mathrm{b}}$} \\
\hline & OR & $95 \% \mathrm{Cl}$ & OR & $95 \% \mathrm{Cl}$ & OR & $95 \% \mathrm{Cl}$ & OR & $95 \% \mathrm{Cl}$ \\
\hline \multicolumn{9}{|l|}{ Objective - Entrance section } \\
\hline Few barriers & 1.0 & & 1.0 & & 1.0 & & 1.0 & \\
\hline Intermediate barriers & 1.4 & $0.8-2.5$ & 1.3 & $0.7-2.4$ & 1.7 & $0.7-3.8$ & 1.0 & $0.4-2.7$ \\
\hline Multiple barriers & 2.3 & $1.4-3.8$ & 1.8 & 1.04-3.1 & 2.3 & $1.1-5.1$ & 1.9 & $0.8-4.3$ \\
\hline \multicolumn{9}{|l|}{ Objective - Exterior section } \\
\hline Few barriers & 1.0 & & 1.0 & & 1.0 & & 1.0 & \\
\hline Intermediate barriers & 0.7 & $0.4-1.1$ & 0.6 & $0.4-1.1$ & 0.4 & $0.2-.9$ & 1.0 & $0.5-2.1$ \\
\hline Multiple barriers & 0.6 & $0.4-.96$ & 0.6 & $0.4-.97$ & 0.6 & $0.3-1.2$ & 0.6 & $0.3-1.4$ \\
\hline \multicolumn{9}{|l|}{ Perceived - Entrance-related } \\
\hline No & 1.0 & & 1.0 & & 1.0 & & 1.0 & \\
\hline Yes & 1.9 & $1.2-3.0$ & 1.6 & $1.01-2.5$ & 1.4 & $.7-2.5$ & 1.1 & $.5-2.5$ \\
\hline
\end{tabular}


Figure 1. The odds ratios and $95 \%$ confidence intervals for reporting moving out-of-home less than daily in groups of a) perceived entrance-related environmental barriers (yes vs. no) or tertiles of objectively recorded environmental barriers (few, intermediate vs. multiple) b) at the entrance or c) in the exterior surroundings in participants with lower extremity performance above or below the median ( $N=836)$. NOTE: The bivariable logistic regression analyses were adjusted for age, sex, number of diseases, cognitive function, month of assessment, type of neighborhood, and years lived in the home. Participants with lower extremity performance at the median (Short Physical Performance Battery score 10) or above and few or no environmental barriers composed the reference group. If the confidence interval does not cross the OR=1 reference line $p<.05$.

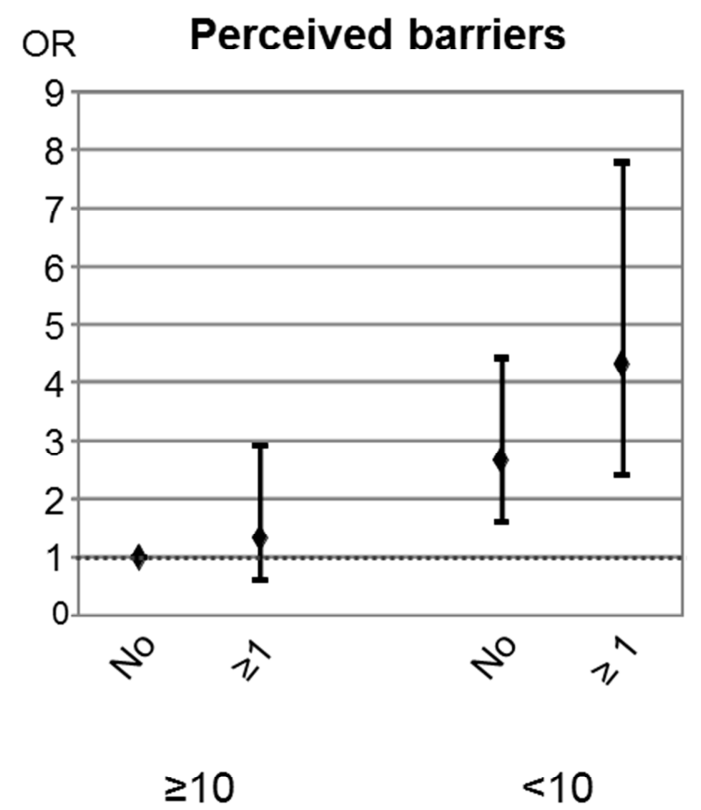

a)

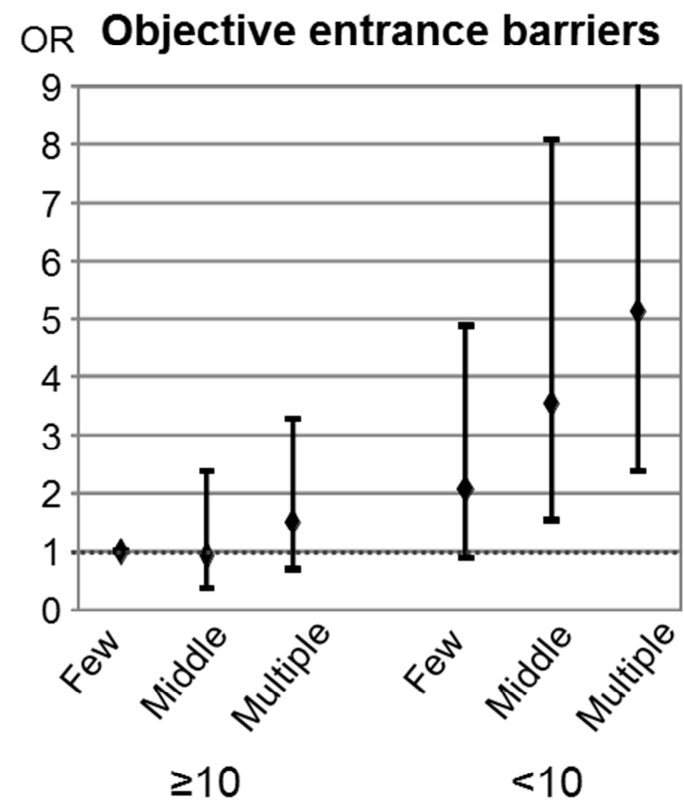

b)
Lower extremity function

\section{OR Objective exterior barriers}

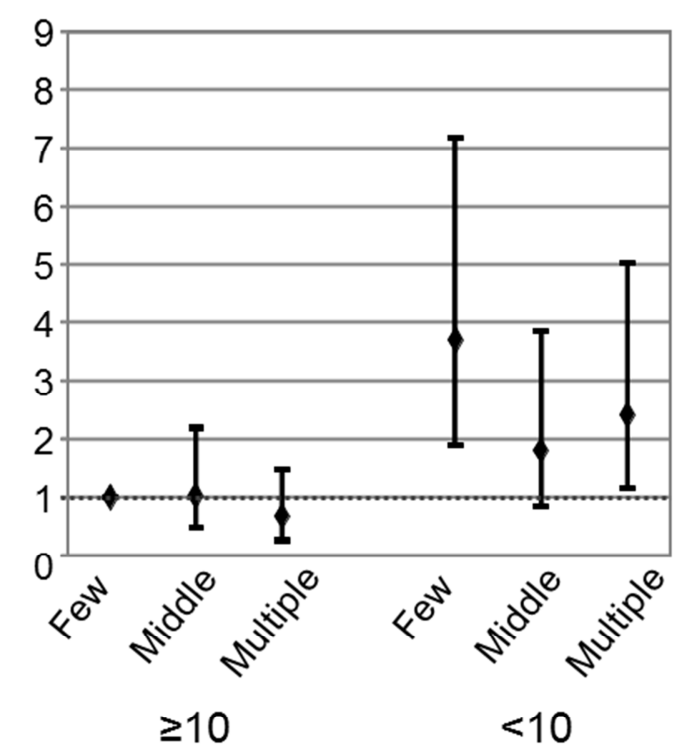

Lower extremity function c) 
Figure 1 shows the combined effects of lower extremity performance and environmental barriers. The OR for reporting moving out-of-home less than daily were only statistically significantly higher only among those with a lower extremity performance below the median. The OR increased further for participants that perceived entrance-related environmental barriers or were living in a home with a higher number of objectively recorded environmental barriers at the entrance. For objectively recorded environmental barriers in the exterior surroundings, the OR for reporting out-of-home mobility less than daily was higher among those with lower extremity performance below the median than among those with lower extremity performance below the median and living in homes with few of such barriers. In contrast, the OR was not or marginally higher in those living in homes with higher numbers of objectively recorded environmental barriers compared to those with lower extremity performance below the median and living in homes with few of such barriers.

\subsection{DISCUSSION}

The current study expands the current knowledge on the relationship between objectively recorded and perceived environmental barriers as well as on the association between environmental barriers and outof-home mobility in old age. Objectively recorded and perceived entrance-related barriers were only weakly associated with each other. Still, both higher numbers of objectively recorded environmental barriers at the home entrance and the presence of perceived entrance-related barrier(s) may limit out-ofhome mobility especially among older people with lower extremity performance limitations. In contrast, moving out-of-home daily was more likely to occur among people with poorer lower extremity performance who lived in a home with more objective environmental barriers in the exterior surroundings.

In the current study, objectively recorded environmental barriers at the entrance were associated with outof-home mobility, but not among those without lower extremity performance limitations. This is in line with the person-environment fit theory ${ }^{15}$ and previous studies showing that the number of environmental barriers recorded per se was not associated with health or physical activity. ${ }^{16,26}$ The magnitude of accessibility problems, which takes into account the functional limitations of an individual and the environmental aspects, has been associated with both factors. ${ }^{22,26}$ In addition, Yang et al. ${ }^{11}$ showed that the frequency of participation in community activities was related to certain home features, other than those related specifically to the entrance, among those with mobility limitation. According to the personenvironment fit theory and the model of selective optimization and compensation, balance needs to be attained between an individual's capabilities and the environmental demands for a certain behavior to occur. ${ }^{15,21}$ Consequently, even in the presence of age-related decreases in functional capacity, barrierfree entrances may prevent changes in behavior, such as a reduction in out-of-home mobility of older people. ${ }^{13}$ This is important considering the fact that leaving the home has been shown to increase the 
level of physical activity of older individuals, ${ }^{2,3}$ which may have important health benefits. ${ }^{4,36,37}$ However, longitudinal studies are needed to confirm the suggested causal relationship.

The fact that the relationship between objectively recorded environmental barriers in the close exterior surroundings of the home and moving out-of-home daily was not in the expected direction deserves attention. That is, living in a home with multiple environmental barriers in the close exterior surroundings did not increase the odds for lower frequency of out-of-home mobility among those with lower extremity performance limitations. In contrast, among those with lower extremity performance limitations, living in a home with few environmental barriers in the close exterior surroundings posed the highest odds for a lower frequency of out-of-home mobility (Table 3, Figure 1). One potential explanation for this finding may be that the initial purpose of the screening tool was to assess environmental impact on managing activities of daily living and specific routes related to such activities. ${ }^{33}$ Since we assessed the association between objectively recorded environmental barriers in the close exterior surroundings with frequency of out-of-home mobility in general, not all items in the Housing Enabler section (e.g. accessibility of the garbage bin) may have been relevant for this outcome. Moreover, older people with lower extremity performance limitations often use mobility devices to support out-of-home mobility to bridge the gap between their capacity and the environment. ${ }^{21,38}$ Using such devices influences the person-environment relation and behavioral outcomes. ${ }^{39}$ Further studies are needed to confirm our findings regarding environmental barriers in the exterior surroundings of the home.

In line with previous research, the correlation between objectively recorded and perceived environmental barriers was rather weak ${ }^{23-25}$ and independent of lower extremity performance. Partly, the low correlation might be due to the fact that the items included in the scales used were not equal. Yet, both objectively recorded and perceived entrance-related barriers were associated with out-of-home mobility behavior. Perceived environmental barriers, that implicitly account for an individuals' functional capacity, were associated with going out-of-the-home less than daily, but only in the analyses including all participants. This potentially suggests that awareness of environmental barriers may precede an actual change in behavior. ${ }^{40}$ Maintaining out-of-home mobility enables participation in meaningful activities and is necessary for running errands, especially among those living alone. ${ }^{6,41}$ Consequently, an individual may use compensation strategies to overcome environmental barriers (e.g. use of mobility devices) prior to modifying personal goals and restricting out-of-mobility. ${ }^{13,21}$

Although others have put forward that environmental barriers, such as stairs, may also provide a training effect, ${ }^{42}$ the present study supports the idea that design of home entrances that accommodates the needs of people with reduced functional capacity enhances older people's possibilities for out-of-home mobility. The trend of aging in place, that often incorporates new initiatives of accessible housing, alludes to this idea. Our study participants had been living in their current home on average for 22.9 years. Thus their 
homes were likely built in a time period in when minimizing environmental barriers was not high on the agenda. Consequently, only a very small proportion of the participants' homes had barrier-free entrances or exterior surroundings, according to the current national guidelines for housing design as assessed with the Housing Enabler screening tool. ${ }^{32,33}$ Other studies have also shown that older people often live in homes with environmental barriers and that person-environment fit is not often attained. ${ }^{17,25,27,43}$

This study was based on large population sample with very few missing data. However, the study sample comprised relatively well-functioning older people. Including more frail people would allow studying the frequency of moving out-of-home instead of comparing people who went out-of-home daily vs. less than daily. Still, previous studies have shown that not leaving the home daily increases the odds for poorer health and functioning. ${ }^{4}$ In terms of study limitations, unfortunately, the lack of correspondence between the separate items of the objective assessment and the self-rating of perceived environmental barriers did not allow for direct comparison.

\subsection{CONCLUSIONS}

Objective and perceived environmental barriers were only weakly associated with each other. However, perceived entrance-related environmental barriers and objective environmental barriers at the entrance may hinder community-dwelling older people to move out-of-home daily especially when their functional capacity is compromised. In contrast, environmental barriers in the exterior surroundings did not seem to compromise out-of-home-mobility. Furthermore, this study shows that especially when objective environmental barriers are studied it is necessary to account for functional capacity in the analyses. While this study was based on cross-sectional analyses, intervention studies and longitudinal studies are needed to determine whether home modifications or barrier-free home environments may prevent or postpone declines in out-of-home mobility accompanying old age and eventually home confinement.

\subsection{ACKNOWLEDGEMENTS}

We thank the participants for their time and effort to participate in our study. Gerontology Research Center is a joint effort between the University of Jyväskylä and the University of Tampere.

Funding: This work was supported by the Academy of Finland [grant number 255403] to (TR) and [grant number 285747] to (MR); the Finnish Ministry of Education and Culture to (TR) and to (EP); the Ribbingska Foundation in Lund, Sweden to (SI); and the University of Jyväskylä. 


\subsection{REFERENCES}

1. Rantanen T, Guralnik JM, Sakari-Rantala R, et al. Disability, physical activity, and muscle strength in older women: The women's health and aging study. Arch Phys Med Rehabil. 1999;80:130-5.

2. Davis MG, Fox KR, Hillsdon M, et al. Getting out and about in older adults: The nature of daily trips and their association with objectively assessed physical activity. Int J Behav Nutr Phys Act. 2011;8:116.

3. Portegijs E, Tsai LT, Rantanen T, Rantakokko M. Moving through greater life-space areas and objectively measured physical activity of older people. Plos One. 2015:e0135308.

4. Shimada $\mathrm{H}$, Ishizaki $T$, Kato $M$, et al. How often and how far do frail elderly people need to go outdoors to maintain functional capacity? Arch Gerontol Geriatr. 2010;50:140-6.

5. Fujita K, Fujiwara Y, Chaves PH, Motohashi Y, Shinkai S. Frequency of going outdoors as a good predictors for incident disability of physical function as well as disability recovery in community-dwelling older adults in rural japan. J Epidemiol. 2006;16:261-70.

6. Satariano WA, Guralnik JM, Jackson RJ, Marottoli RA, Phelan EA, Prohaska TR. Mobility and aging: New directions for public health action. Am J Public Health. 2012;102:1508-15.

7. Baker PS, Bodner EV, Allman RM. Measuring life-space mobility in community-dwelling older adults. $J$ Am Geriatr Soc. 2003;51:1610-4.

8. Simonsick EM, Guralnik JM, Volpato S, Balfour J, Fried LP. Just get out the door! importance of walking outside the home for maintaining mobility: Findings from the women's health and aging study. $J$ Am Geriatr Soc. 2005;53:198-203.

9. Iwarsson S, Isacsson A. Quality of life in the elderly population: An example exploring interrelationships among subjective well-being, ADL dependence, and housing accessibility. Arch Gerontol Geriatr. 1998;26:71-83.

10. Rantakokko M, Iwarsson S, Portegijs E, Viljanen A, Rantanen T. Associations between environmental characteristics and life-space mobility in community-dwelling older people. J Aging Health 2015;27:606-21

11. Yang HY, Sanford JA. Home and community environmental features, activity performance, and community participation among older adults with functional limitations. J Aging Res. 2012;2012:625758.

12. Ward Thompson C. Activity, exercise and the planning and design of outdoor spaces. J Environ Psychol. 2013;34:79-96.

13. Rantakokko M, Portegijs E, Viljanen A, Iwarsson S, Rantanen T. Mobility modification alleviates environmental influence on incident mobility difficulty among community-dwelling older people: A two-year follow-up study. PLoS One. 2016;11:e0154396.

14. Van Cauwenberg J, De Bourdeaudhuij I, De Meester F, et al. Relationship between the physical environment and physical activity in older adults: A systematic review. Health Place. 2011;17:458-69. 
15. Lawton MP, Nahemow L. Ecology and aging process. In: Eisdorfer C, Lawton MP, eds. The psychology of adult development and aging. Washington DC: American Psychology Association; 1973:619-74.

16. Benzinger $\mathrm{P}$, Iwarsson $\mathrm{S}$, Kroog $\mathrm{A}$, et al. The association between the home environment and physical activity in community-dwelling older adults. Aging Clin Exp Res. 2014;26:377-85.

17. Iwarsson S, Horstmann V, Carlsson G, Oswald F, Wahl HW. Person-environment fit predicts falls in older adults better than the consideration of environmental hazards only. Clin Rehabil. 2009;23:558-67.

18. Rantakokko M, Iwarsson S, Kauppinen M, Leinonen R, Heikkinen E, Rantanen T. Quality of life and barriers in the urban outdoor environment in old age. J Am Geriatr Soc. 2010;58:2154-9.

19. Lord SR, Menz HB, Sherrington C. Home environment risk factors for falls in older people and the efficacy of home modifications. Age Ageing. 2006;35 Suppl 2:ii55-ii59.

20. Portegijs E, Rantakokko M, Edgren J, et al. Effects of a rehabilitation program on perceived environmental barriers in older patients recovering from hip fracture: A randomized controlled trial. Biomed Res Int. 2013;2013:769645.

21. Baltes PB, Baltes MM. Psychological perspectives on successful aging: The model of selective optimization with compensation. In: Baltes PB, Baltes MM, eds. Successful aging: Perspectives from the behavioral sciences. Cambridge: Cambridge University Press; 1990:1-34.

22. Yen IH, Michael YL, Perdue L. Neighborhood environment in studies of health of older adults: A systematic review. Am J Prev Med. 2009;37:455-63.

23. Gebel K, Bauman A, Owen N. Correlates of non-concordance between perceived and objective measures of walkability. Ann Behav Med. 2009;37:228-38.

24. Byles JE, Mackenzie L, Redman S, Parkinson L, Leigh L, Curryer C. Supporting housing and neighbourhoods for healthy ageing: Findings from the housing and independent living study (HAIL). Australas J Ageing. 2014;33:29-35.

25. Carter SE, Campbell EM, Sanson-Fisher RW, Redman S, Gillespie WJ. Environmental hazards in the homes of older people. Age Ageing. 1997;26:195-202.

26. Oswald F, Wahl HW, Schilling O, et al. Relationships between housing and healthy aging in very old age. Gerontologist. 2007;47:96-107.

27. Wahl HW, Fange A, Oswald F, Gitlin LN, Iwarsson S. The home environment and disability-related outcomes in aging individuals: What is the empirical evidence? Gerontologist. 2009;49:355-67.

28. Iwarsson S, Horstmann V, Slaug B. Housing matters in very old age - yet differently due to ADL dependence level differences. Scand J Occup Ther. 2007;14:3-15.

29. Rantanen T, Portegijs E, Viljanen A, et al. Individual and environmental factors underlying life space of older people - study protocol and design of a cohort study on life-space mobility in old age (LISPE).

BMC Public Health. 2012;12:1018. 
30. Guralnik JM, Simonsick EM, Ferrucci L, et al. A short physical performance battery assessing lower extremity function: Association with self-reported disability and prediction of mortality and nursing home admission. J Gerontol. 1994;49:M85-94.

31. Mänty M, Sihvonen S, Hulkko T, Lounamaa A, eds. läkkäiden henkilöiden kaatumistapaturmat. opas kaatumisten ja murtumien ehkäisyyn. 2nd ed. Kansanterveyslaitoksen julkaisuja; 2007.

32. Iwarsson S, Slaug B, Malmgren Fänge A. The housing enabler screening tool: Feasibility and interrater reliability in a real-estate company practice context. J App/ Gerontol. 2011;31:641-60.

33. Iwarsson S, Slaug B, Haak M. Current developments of the housing enabler methodology. Br J Occup Ther. 2012;75:517-21.

34. Viljanen A, Kulmala J, Rantakokko M, Koskenvuo M, Kaprio J, Rantanen T. Fear of falling and coexisting sensory difficulties as predictors of mobility decline in older women. J Gerontol A Biol Sci Med Sci. 2012;67:1230-7.

35. Folstein MF, Folstein SE, McHugh PR. "Mini-mental state". A practical method for grading the cognitive state of patients for the clinician. J Psychiatr Res. 1975;12:189-98.

36. Varma VR, Tan EJ, Wang T, et al. Low-intensity walking activity is associated with better health. $J$ Appl Gerontol. 2014;33:870-87.

37. Brach JS, Simonsick EM, Kritchevsky S, Yaffe K, Newman AB, Health, Aging and Body Composition Study Research Group. The association between physical function and lifestyle activity and exercise in the health, aging and body composition study. J Am Geriatr Soc. 2004;52:502-9.

38. Bateni H, Maki BE. Assistive devices for balance and mobility: Benefits, demands, and adverse consequences. Arch Phys Med Rehabil. 2005;86:134-145.

39. Iwarsson S, Stathi A, Löfqvist C. Mobility in outdoor environments in old age. In: Rowles G, Bernard $\mathrm{M}$, eds. Environmental gerontology: Making meaningful places in old age. New York: Springer Publishing Company; 2013:175-98.

40. Peel N, Steinberg M, Williams G. Home safety assessment in the prevention of falls among older people. Aust N Z J Public Health. 2000;24:536-9.

41. Tsai LT, Rantakokko M, Portegijs E, et al. Environmental mobility barriers and walking for errands among older people who live alone vs. with others. BMC Public Health. 2013;13:1054.

42. Bean J, Herman S, Kiely DK, et al. Weighted stair climbing in mobility-limited older people: A pilot study. J Am Geriatr Soc. 2002;50:663-70.

43. Gill TM, Robison JT, Williams CS, Tinetti ME. Mismatches between the home environment and physical capabilities among community-living older persons. J Am Geriatr Soc. 1999;47:88-92. 